\title{
A QUANTITATIVE ANALYSIS OF PROTOTYPE USE FOUND IN STUDENTS' DESIGN PROJECTS
}

\author{
Konstantinos PETRAKIS ${ }^{1}$, Andrew WODEHOUSE ${ }^{1}$ and Abigail HIRD ${ }^{2}$ \\ ${ }^{1}$ University of Strathclyde \\ ${ }^{2}$ Innovate UK, Knowledge Transfer Network
}

\begin{abstract}
Prototyping constitutes an inseparable part of engineering design academic courses and a significant topic of design education. According to relevant literature, especially physical prototypes along with the actual process of model building have been proved to be very beneficial as they boost students' creativity and resourcefulness and assist them in evaluating their ideas better. Nevertheless, their use of prototypes has still not been explored in depth to be clearly understood and transformed into explicit instructions for informing design education. The main goal of this study is to explore how students make use of prototypes and understand the reasoning behind their prototyping activities. This is achieved by identifying instances of prototype use in projects and performing a quantitative analysis according to the explicit purpose of their prototyping activities. The results confirm students' limited scope of prototype use during the early design stages, show their unfamiliarity with prototypes' less explored roles and present the purposes which are mostly used during the projects. Such results could lead to the creation of a framework of guidelines which presents the prototyping process in a more structured way, aimed at engineering design students and design education practices.
\end{abstract}

Keywords: Prototyping, engineering design, prototype purpose, student projects, design education

\section{INTRODUCTION}

Prototyping, the procedure of creating a prototype, constitutes an integral and inseparable aspect of any product development process in both professional and academic practices. Particularly in engineering design courses, students have to build a wide range of different prototypes during their projects. However, although prototyping is also regarded as a major topic of design education, it is regarded as an activity which has not been examined thoroughly [1], [2]. A prototype can generally be defined as "an approximation of the product along one or more dimensions of interest" [3] or "an artefact that approximates a feature (or multiple features) of a product" [4]. Some also state that any type of design representation that embodies aspects of functionality and look-and-feel of the final product can be considered as a prototype, including sketches and rough models [5]. Contrariwise, other state the difference between a prototype and a concept is the fact that the prototype can be tested, as opposed to a simple idea [6]. In this work, we will be considering every three-dimensional physical model found in students' work which carries either functional or aesthetical features of the final design as a prototype, from rough mock-ups to detailed functional models, however excluding sketches and virtual representations.

The main goal of this study is to understand the reasoning behind students' prototyping activities and examine how they use prototypes for the delivery of a final product. This is achieved by identifying instances of prototype use in their projects and performing a quantitative analysis which concentrates more on the explicit purpose of their prototyping activities.

\section{LITERATURE REVIEW}

\subsection{Prototyping in Engineering Design Education}

Prototyping activities are considered as a major part of design education; however the use of prototypes by students has not been thoroughly explored in order to be explicitly understood [1]. Through the use of prototypes, design students can simulate features of the final design with the aim of providing solid 
answers to questions and minimising risk and uncertainty during their projects [7]. Particular emphasis has also been given to prototyping's cognitive benefits, namely the reasoning of a design problem and its space, visualisation and communication of design ideas as well as supporting students' experiential and practical learning and understanding of the design problem during the early stages [8], [9]. Furthermore, prototyping is clearly associated with knowledge and objective learning, as suggested by a study applied in academic contexts. Functioning as an enabler for students' thoughts, prototypes allow better communication amongst the project's stakeholders, such as students, teachers and potential users and support students in tackling challenging problems [10]. Physical prototypes and models in particular have been proved to be more beneficial for students comparing to other forms of representations such as sketches, and help them to find innovative ways to solve design problems [11]. The actual process of model building facilitates them in the evaluation of their ideas, aids in preventing potential faults early in the process and helps them to explore a concept's features and materials behaviour in real-world engineering situations. In general, apart from improving their designing and building skills, modelmaking can also enhance students' creative thinking and increase their self-confidence [11]. Moreover, both creating and testing physical models is reported to be very valuable for students during the idea generation process as it results in producing more useful and functional ideas while alleviating design fixation to a significant extent. Also, through the use of physical representations, their reasoning processes are also supported and improved [12].

As far as design education is concerned, in order to provide valuable insights within academic environments, we must identify the best prototyping professional practices, so as to transform them into instructional frameworks [1]. In order to deliver effective teaching of design courses and properly incorporate prototyping into them, the first step, undeniably, is to understand the engineering design process [11]. Also, it is vital to examine how various prototyping techniques can stimulate students' learning and explicitly relate prototyping exercises to the processes of learning by reflection and learning by thinking [13]. Students also need clear guidance regarding the positive effects of prototypes, but most importantly how and when to operate them during the process, as for the successful delivery of a design, it is crucial to build the right type of prototype for the right purpose [9], [12]. The activity of defining this purpose requires reflective thinking, which comes less naturally to students and inexperienced designers in general. Consequently, there is a clear lack of a prototyping strategy that is adjusted to design education needs in order to foster students' prototyping results and further develop their design skills. The process of modelmaking, particularly, is also considered as "an often overlooked pedagogical tool that can enhance the engineering design process for students" [11]. Such structured approaches are already applied in some academic contexts, yet there are still some gaps and weaknesses that have to be addressed [10].

\subsection{Studies in Students' Prototyping Activities}

In the existing literature we can find some efforts in trying to capture understand and analyse prototyping activities by performing studies involving engineering students. To begin with, studies have tried to characterise prototypes created by mechanical engineering students during a year-long project based course, by categorising activities such as sketching, conceptual prototyping, benchmarking and CAD into design thinking and engineering thinking [2]. Another study aims to compare the different perceptions and usages of prototypes between students and professionals through the application of a quantitative approach based on surveys and questionnaires. This study offers a significant input in the field of design education as it results in several explicit prototyping instructions arising from unexplored opportunities by students during their prototyping activities [1]. The relationships between students' prototyping activities and the design outcome have also been explored, with a specific focus given on the number of prototype parts and the time spent on the process. Key findings indicate that prototypes with fewer parts result in better design outcomes and that the time spent on prototyping is not correlated with the project's success [7]. Another student-based study resulted in the confirmation that by applying structured methods for focused prototyping they managed to raise students' awareness and therefore facilitating them in creating better quality prototypes [14]. Students' use of prototypes has been also examined extensively through a comprehensive investigation of their prototyping activities using semistructured interviews. Respected results are provided regarding the conceptualisation of prototypes by inexperienced designers, the process stages in which they tend to prototype the most, as well as how they use prototypes in order to communicate concepts and engage with stakeholders [15]. 
All of the aforementioned studies provide significant understandings of students' prototype usage; nevertheless, most of them are based on qualitative approaches and use either interviews or questionnaires for the collection of the data. Therefore, for the purpose of this study we apply a quantitative way of collecting and analysing data which builds up on our previous work and focuses on the purpose factor of prototyping activities along with its relationships with project effectiveness.

\section{METHODOLOGY}

This study was performed through the review of individual student projects in the Department of Design, Manufacturing and Engineering Management at the University of Strathclyde. The course's objective is the delivery of a product that represents a solution to a design problem, as seen in Figure 1. Students have been specifically encouraged by their instructors regarding the importance of prototyping and modelmaking at all stages of the design process, with a more specific focus on early exploration stages. The course is divided into Stage 1 ending in December and Stage 2 ending in May of the academic year. Initially, 133 student projects were reviewed, however that number was later reduced to 120 as 13 of the projects did not include a prototype or a physical model, according to our used definition. The total of 120 examined projects have been undertaken by both $4^{\text {th }}$ and $5^{\text {th }}$ year students of 3 courses; 68 in Product Design Engineering (PDE), 26 in Sports Engineering (SE) and 26 in Product Design and Innovation (PDI) and all of them were anonymised prior to the initiation of the study.

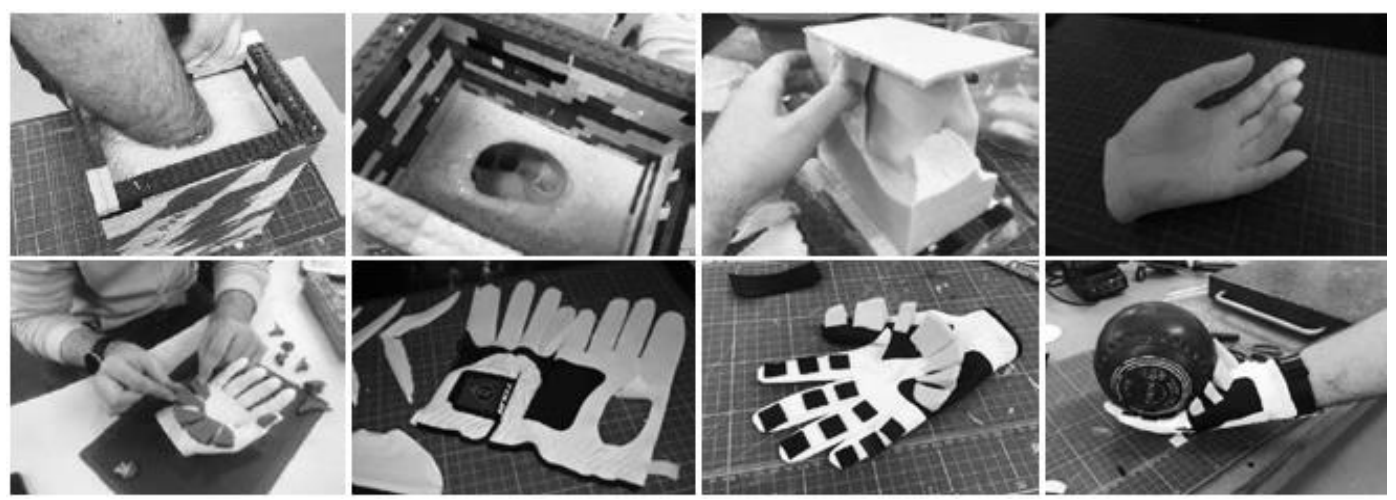

Figure 1. The Prototyping Process of a Sports Engineering Student

The most extensive part of this survey focuses on defining the purpose of prototype use documented in the students' work. This factor is based on the concept of "Purposeful Prototyping" and an already created list of 23 prototype purposes (Table 1), both developed in the authors' previous work. These purposes arise from prototypes' major roles, namely Learning, Communication, Demonstration and Integration, as well as less explored roles such as Refinement, Exploration and Elicitation. The developed purposes can be also regarded as "sub-roles" or "functions" according to the more specific areas of each role where prototypes are proven to be supportive to designers' needs. More specifically, the student projects were assessed depending on how many and which of the explicit purposes are identified during the prototyping activities found in them. As this study is built upon previous work, this was done in order to define the most used and the most significant purposes of initiating the building of a physical model during a project. Another reason of initiating this research is also to evaluate the practicality and the accuracy of the developed list and define any potential changes that will improve its effectiveness for future applications. Such results will strongly contribute in the future development of a structured prototyping strategy aimed at design students.

\section{RESULTS AND DISCUSSION}

As it is also mentioned earlier, in 13 of the projects there are not any prototypes found as far as physical models are concerned. According to the student reports, this occurs because of time constraints which are due to poor project management, as well as the large size and high cost of specific parts or materials which did not even allow the creation of scaled models. Other reasons include unfeasible physical testing and the nature of the assignment e.g. the design of a mobile application or coding-related projects.

During Stage 1, only $13 \%$ of the students endorsed into prototyping activities. Such initial prototypes include mainly modifications on existing products, rough mock-ups made of cardboard, foam or paper as well as empathic modelling exercises. Their main purposes are to understand and test basic 
mechanisms as well as early user interaction for testing ergonomics. The results show that all of these 15 students managed to deliver successful projects; 6 of them marked with 65 and 9 of them marked with 70 or above.

Table 1. List of Purposes and Usage by Students

\begin{tabular}{|r|l|r|}
\hline$\#$ & Purposes & Use \% \\
\hline $\mathbf{1}$ & Answer questions regarding the functionality and technical elements. & 71.7 \\
\hline $\mathbf{2}$ & Answer questions regarding users' requirements and preferences. & 64.2 \\
\hline $\mathbf{3}$ & Reveal information about unknown factors that may affect performance. & 20.8 \\
\hline $\mathbf{4}$ & Provide insights to business-related concerns (cost, tooling, etc.). & 11.7 \\
\hline $\mathbf{5}$ & Explain a concept to stakeholders by demonstrating how it functions. & 65.0 \\
\hline $\mathbf{6}$ & Communicate aesthetics in order to experience the product's look and feel. & 69.2 \\
\hline $\mathbf{7}$ & Get feedback in relation to functionality, performance or aesthetics. & 84.2 \\
\hline $\mathbf{8}$ & Use the prototype as a means of visual aid for initiating discussion. & 14.2 \\
\hline $\mathbf{9}$ & Use the prototype as a persuasion tool during design meetings. & 33.3 \\
\hline $\mathbf{1 0}$ & Identify features with the most significant impact to performance. & 42.5 \\
\hline $\mathbf{1 1}$ & Validate specifications and define margins of improvement. & 82.5 \\
\hline $\mathbf{1 2}$ & Gather experimental data through a series of testing. & 66.7 \\
\hline $\mathbf{1 3}$ & Reveal possible errors during fabrication of the prototype. & 14.2 \\
\hline $\mathbf{1 4}$ & Evaluate overall aesthetics by developing a whole assembly prototype. & 30.8 \\
\hline $\mathbf{1 5}$ & Ensure compatibility between parts and between parts and system. & 40.0 \\
\hline $\mathbf{1 6}$ & Configure functionality and performance of the whole assembly. & 46.7 \\
\hline $\mathbf{1 7}$ & Set milestones to assist the planning of PD process in terms of time \& cost. & 1.7 \\
\hline $\mathbf{1 8}$ & Establish forward progress by confirming a certain degree of functionality. & 15.0 \\
\hline $\mathbf{1 9}$ & Enhance ideation and develop a wider range of concepts. & 26.7 \\
\hline $\mathbf{2 0}$ & Compare characteristics and performance to competitor products. & 6.7 \\
\hline $\mathbf{2 1}$ & Compare prototypes for informing concept selection. & 45.0 \\
\hline $\mathbf{2 2}$ & Observe users' interactions in order to uncover unknown requirements. & 17.5 \\
\hline $\mathbf{2 3}$ & Prioritise requirements and identify the target group of users. & 9.2 \\
\hline & & \\
\hline
\end{tabular}

Regarding Stage 2, the most popular purpose (84\%) for building a prototype amongst students of all 3 courses is getting feedback in relation to functional and aesthetic features of their product and falls into the role category of Communication. In the case of these projects, feedback is acquired by either potential users, fellow colleagues in the form of focus groups or by their instructors during critique presentations. Also, the majority $(82.5 \%)$ of the students need the prototypes to validate specifications and a significant percentage of them (71.7\%) to find answers regarding the product's functionality. Many students also use prototypes to communicate their concepts' both functionality and look and feel aspects, by $65 \%$ and $69.2 \%$ respectively. All the above results indicate that students do not make full use of prototyping's benefits and agree with other studies that have proved their narrow scope in prototyping [1], as their most used purposes, such as feedback, testing and validation of functionality and requirements fall into the most common prototype uses found in the literature. As far as Demonstration is regarded, $15 \%$ of the students prototype to establish forward progress and only $1.7 \%$ of them use prototypes as milestones in order to plan their process, which justifies to an extent the unsatisfactory project management seen in a lot of projects. Moreover, the very low percentages $(14.2 \%)$ of revealing potential errors during the prototype's fabrication validates the fact that the model building process is still overlooked, and students do not apply prototyping in order to prevent early faults during the fabrication of the product.

As far as the early process stages are concerned, students' primary purpose is to prototype their ideas in order to compare them and proceed with concept selection. However, not even half of them (45\%) apply prototyping, with other methods such as dot-sticking and weighting matrices being the most common. As it is seen in Figure 2 below, purposes 3, 13, 19 and 22 which are strongly related to the early stages of the process, seem to be amongst the least used by students. This result displays that students from all courses still do not value the benefits of prototypes during the early design stages of exploring the design space, a matter that has to be addressed by design education. PDI students seem to use prototypes more to enhance their ideation and this is somehow justified by the more creative nature of the course, 
however they do not greatly apply them to elicit user requirements. At this point we must clarify that the difference between purposes 2 and 22 has to do with the validation and the elicitation of user requirements respectively. On the other hand, revealing unknown performance factors (3) as well as purposes 10, 11 and 12 which are related to testing and refinement are more valued by PDE and SE students as they tend to focus more on technical features. The same happens with the gathering of experimental data which is the most popular amongst SE students (96\%). Regarding the role of Integration, PDI students focus more on the aesthetics of the overall assembly whereas PDE students care most about assembly performance and SE students focus on compatibility of parts.

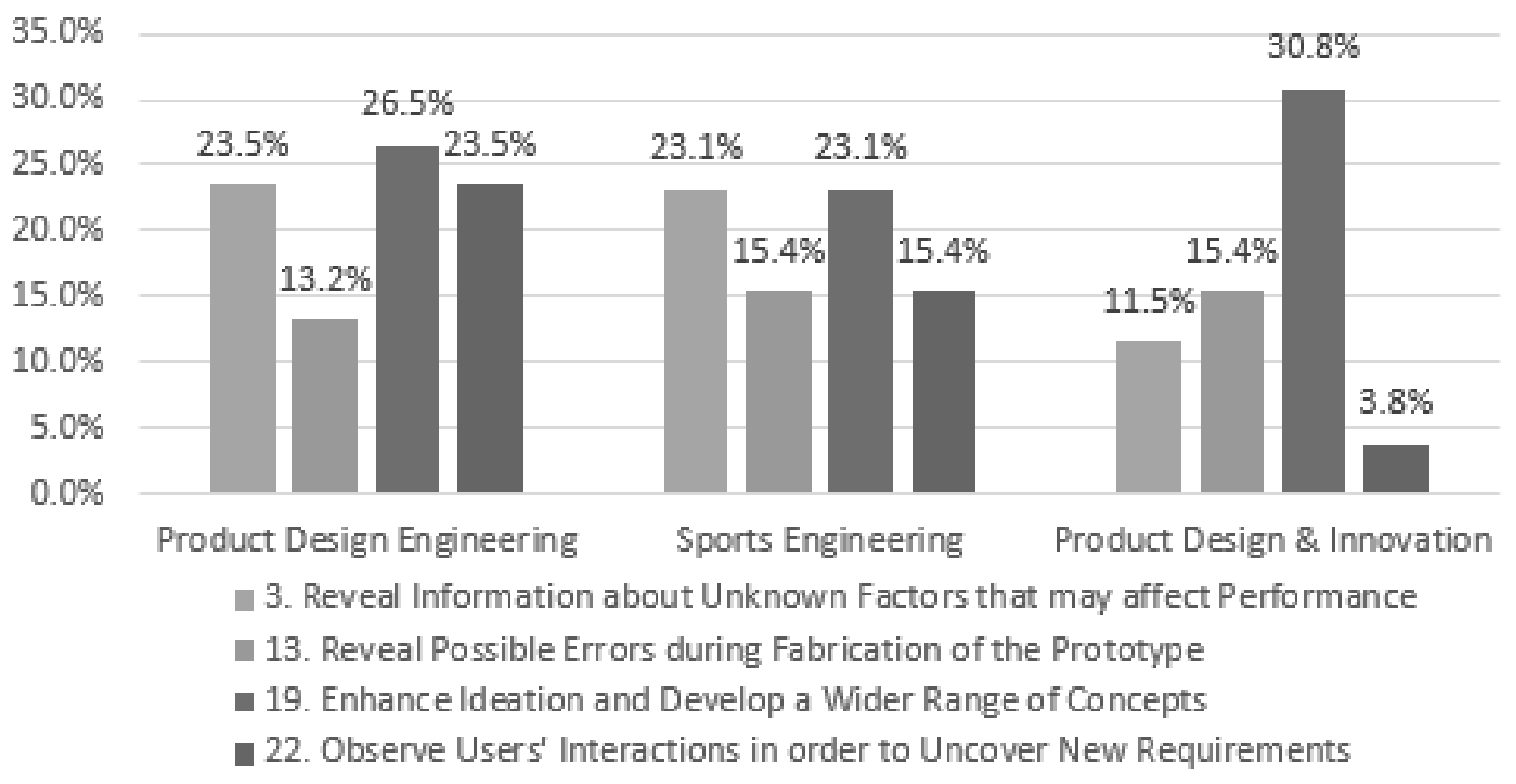

Figure 2. Uses of Early Stage Purposes by 3 DMEM Courses

Finally, as far as the prototyping purposes being used by students and the effectiveness of their projects are concerned, there seems to be a significant correlation between these two factors. In general, it is observed that the majority of the most used purposes are the ones who are being used by the highest marked projects, whereas in contrast, the usage of them in the least effective of the examined projects is significantly lower.

However, as this is an important part of the overall study, extended analysis of these relationships will be conducted during the near future along with the rest of the examined factors. This analysis will provide valuable results in relation to which purposes, and therefore types of prototyping roles, result in students achieving to deliver a successful project. Also, it will show the importance of prototyping purposes in the design project's planning and the way in which they affect the projects' success.

\section{CONCLUSIONS AND FUTURE WORK}

This paper presents an exploration of prototyping instances found in individual projects of engineering design students. A quantitative analysis of the results is performed according to the explicit purpose of prototyping activities. The analysis confirms that students do not make full use of the benefits of prototyping and require more explicit guidelines and encouragement, a fact that provides valuable insights for design education practices. This paper presents the early stages of this research and factors such as project effectiveness, the number of prototypes and the process stages of prototyping are part of future analysis. We also plan to inspect industrial projects, in which student teams cooperate with professional clients and demonstrate representations of their work to them. This would result in more valuable outcomes regarding the purpose of both internal and external communication and especially prototypes' functions as visual aids and persuasion tools. In further future work, students' own reflections and inputs from their instructors on prototype use, through interviews before, during and after the completion of their projects will also facilitate a mixture of quantitative and qualitative research and will produce more validated and enriched results. These results could lead to the development of a 
framework functioning as the basis of a structured prototyping strategy, with a potential to be applied in academic practices and improve the quality of design education.

\section{REFERENCES}

[1] Lauff C., Kotys-Schwartz D. and Rentschler M.E. "Perceptions of Prototypes: Pilot Study Comparing Students and Professionals," in ASME 2017 International Design Engineering Technical Conferences and Computers and Information in Engineering Conference, IDETC/CIE 2017 August 6-9, 2017, Cleveland, Ohio, USA, 2017.

[2] Lande M. and Leifer L. "Prototyping to Learn: Characterising Engineering Students' Prototyping Activities and Prototypes," in International Conference on Engineering Design, ICED09, Stanford, CA, USA, 2009, pp. 507-516.

[3] Ulrich K.T. and Eppinger S.D. Product Design and Development, no. McGraw-Hill Internation Edition-5th Edition. 2012.

[4] Otto K. and Wood K. Product Design: Techniques in Reverse Engineering and New Product Development. 2001.

[5] Gurjar T.P. "Effects of a Structured Prototyping Strategy on Capstone Design Projects," Present. to Fac. Grad. Sch. Univ. Texas Austin, May 2015, 2015.

[6] Camburn B. et al., "Design prototyping methods : state of the art in strategies , techniques , and guidelines," Des. Sci. Vol 3, 2017.

[7] Yang M.C. "A study of prototypes, design activity, and design outcome," Des. Stud. 26 649e669 doi10.1016/j.destud.2005.04.005, vol. 26, pp. 649-669, 2005.

[8] Elsen C., Häggman A., Honda T. and Yang M.C. "Representation in Early Stage Design: An Analysis of the Influence of Sketching and Prototyping in Design Project," in ASME 2012 International Design Engineering Technical Conferences \& Computers and Information in Engineering Conference, August 12-15, 2012, Chicago, IL, USA, 2012, pp. 737-747.

[9] Böhmer A.I., Kayser L., Sheppard S. and Lindemann U. "Prototyping as a thinking approach in design: Insights of problem-solving activities while designing a product," in 2017 International Conference on Engineering, Technology and Innovation (ICE/ITMC), June 2017, 2017, pp. 955963.

[10] Berglund A. and Leifer L. "Why we Prototype ! An International Comparison of the Linkage between Embedded Knowledge and Objective Learning," Eng. Educ. 81, 2-15, DOI 10.11120/ened.2013.00004, 2013.

[11] Lemons G., Carberry A., Swan C. and Rogers C. "The benefits of model building in teaching engineering design,” Des. Stud., vol. 31, no. 3, pp. 288-309, 2010.

[12] Viswanathan V. K. and Linsey J.S. "Enhancing Student Innovation: Physical Models in the Idea Generation Process," in 39th ASEE/IEEE Frontiers in Education Conference, October 18 - 21, 2009, San Antonio, TX, 2009.

[13] Schaeffer J.A. and Palmgren M. "Visionary Expectations and Novice Designers - Prototyping in Design Education," Des. Technol. Educ. an Int. Journal, [S.l.], v. 22, n. 1, may 2017. ISSN 13601431., pp. 1-16, 2017.

[14] Menold J., Jablokow K., Simpson T.W. and Waterman E. "The Prototype for X (PFX) Framework: Assessing Its Impact on Students' Prototyping Awareness," in ASEE's 123rd Annual, Conference and Exposition, New Orleans, LA, June 26-29, 2016, 2016.

[15] Deininger M., Daly S.R., Sienko K.H., Lee J.C. and Street H. "Novice Designers' Use of Prototypes in Engineering Design," Des. Stud., vol. 51, pp. 25-65, 2017. 